\title{
Genograma e ecomapa: desenhando itinerários terapêuticos de família em condição crônica*
}

\author{
Genograma y ecomapa: diseñando itinerarios terapéuticos de familia en condición crónica
}

Genogram and ecomap: drawing therapeutic itineraries for families living in a chronic condition

Cleciene dos Anjos Musquim¹, Laura Filomena Santos de Araújo², Roseny Bellato ${ }^{3}$, Janderléia Valéria Dolina ${ }^{4}$

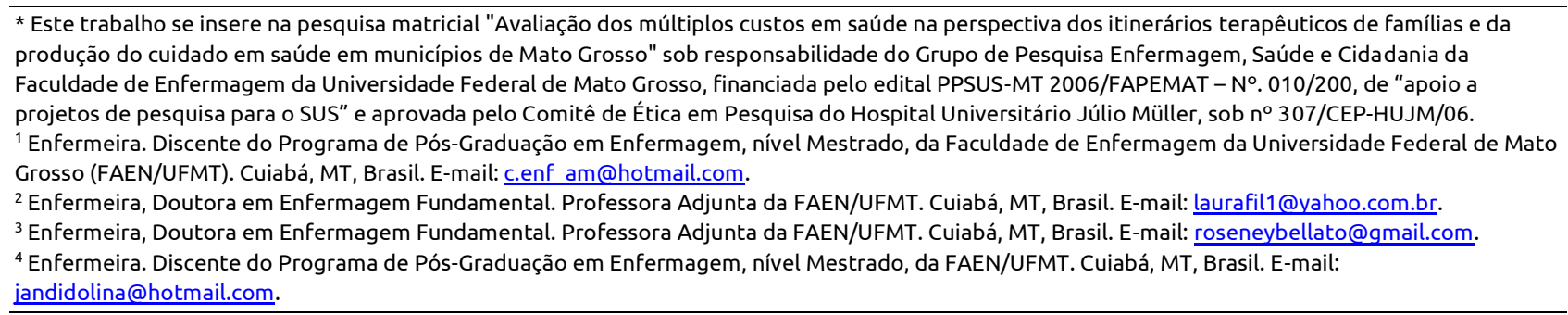

\section{RESUMO}

O presente estudo teve como objetivo discutir a proposição de desenho interativo para as ferramentas de genograma e ecomapa que pudesse representar, ao longo do tempo, o modo como uma família vivencia o adoecimento crônico concomitante em dois de seus membros. Utilizamos a História de Vida Focal como estratégia metodológica para compor os desenhos como parte do Itinerário Terapêutico da família. Estas ferramentas propostas como desenhos interativos foram capazes de sistematizar, sintetizar e conferir visibilidade aos rearranjos familiares e redes para o cuidado tecidas ao longo da experiência de adoecimento. Embora ainda demonstrem limitações quando apresentados de modo impresso, tais desenhos ampliam a capacidade de expressar as diferentes espacialidades e temporalidades dessa experiência, bem como avaliar suportes e recursos existentes para que a família possa cuidar ou buscar o cuidado profissional, possibilitando que possamos pensar novas práticas de atenção em saúde e, nelas, as intervenções de enfermagem.

Descritores: Relações Familiares; Apoio Social; Doença Crônica; Desenhos; Enfermagem.

\section{ABSTRACT}

The objective of the present study was to discuss the proposal of an interactive drawing for the genogram and ecomap tools that could represent, through time, the way that a family experiences the chronic illness affecting two relatives at the same time. We used Focal Life History as the methodological strategy to make the drawings as part of the family's Therapeutic Itinerary. The tools proposed as interactive drawings were able to systemize, synthesize and offer visibility to the family adjustments and care webs woven during their experience of the illness. Despite the persisting limitations when printed, these drawings broaden the capacity to express the different spaces and times of that experience, and to evaluate the existing supports and resources available for the family to provide care themselves or find professional care, thus motivating the thoughts of new health care practices and the involved nursing interventions.

Descriptors: Family Relations; Social Support; Chronic Disease; Drawings; Nursing.

\section{RESUMEN}

El estudio objetivó discutir la proposición de diseño interactivo para las herramientas de genograma y ecomapa que pudiese representar, a lo largo del tiempo, el modo en que una familia experimenta el padecimiento crónico concomitante en dos de sus miembros. Utilizamos la Historia de Vida Focal como estrategia metodológica para componer los diseños como parte del Itinerario Terapéutico familiar. Estas herramientas propuestas como diseños interactivos pudieron sistematizar, sintetizar y hacer visibles las reorganizaciones familiares y redes de cuidado tejidas a lo largo de la experiencia del padecimiento. Aunque aún demuestren limitaciones al presentárselos de manera impresa, tales diseños amplían la capacidad de expresar las diferentes espacialidades y temporalidades de esa experiencia, así como evaluar soportes y recursos existentes para que la familia pueda cuidar o buscar cuidado profesional, ayudando a que podamos pensar en nuevas prácticas de atención en salud y, mediante ellas, las intervenciones de enfermería.

Descriptores: Relaciones Familiares; Apoyo Social; Enfermedad Crónica; Dibujos; Enfermería. 


\section{INTRODUÇÃO}

Este estudo tem como foco a potencialidade do uso do genograma e do ecomapa como ferramentas analisadoras que compõem o Itinerário Terapêutico (IT) na compreensão da experiência de adoecimento crônico de pessoas e famílias ${ }^{(1-2)}$. Tais ferramentas permitem sistematizar, sintetizar e conferir visibilidade aos modos como se organizam as redes para o cuidado à saúde tecidas por essas pessoas, mostrando quem as compõe, a qualidade de suas relações e os significados produzidos na sua contextura(3); auxiliam também na avaliação da composição e organização familiar, sendo uma rica fonte de informação apresentada de forma clara e sucinta ${ }^{(4)}$.

O genograma é um instrumento elaborado por terapeutas familiares e tem sido vastamente utilizado por profissionais de diversas áreas, dentre elas a da saúde, como a enfermagem, psicologia, medicina, serviço social, entre outros ${ }^{(5)}$. Em seu desenho gráfico, representa a composição familiar interna, evidenciando os núcleos de cuidado, do qual participam diferentes pessoas. Nele são empregados símbolos, identificando os diferentes elementos que dão características aos membros familiares e suas relações ${ }^{(6-7)}$. Sua utilização permite compreender dimensões complexas da dinâmica familiar, como os relacionamentos entre seus entes e a comunicação, o adoecimento, equilíbrios e desequilíbrios e os padrões de repetições familiares ${ }^{(8)}$. As relações são simbolizadas por traços ligados entre os familiares que denotam a qualidade das mesmas.

O desenho do ecomapa representa os recursos disponíveis e acessados pela família ${ }^{(1)}$. Na sua construção a família é apresentada no centro e, ao redor, suas redes de relações, que podem ser de vizinhança, de amizade, redes formais e outras. As linhas mostram os tipos de vínculos existentes, sendo que, usualmente, as linhas contínuas representam ligações fortes, as pontilhadas são ligações frágeis, as tênues e cortadas são as estressantes; já o emprego de setas mostra os fluxos de energia ${ }^{(6,8)}$.

Estes desenhos têm sido muito úteis nos estudos de IT desenvolvidos na pesquisa matricial, que tem privilegiado a abordagem da vivência da condição crônica que requer gerenciamento continuado, tanto pelas pessoas e suas famílias, como pelos serviços e profissionais de saúde. A designação condição crônica abrange agravos de saúde não transmissíveis, transmissíveis persistentes, distúrbios mentais de longo prazo, deficiências físicas e estruturais contínuas, tendo como característica comum a persistência no tempo, podendo manter-se por vários anos ou décadas, havendo a necessidade de cuidados constantes ${ }^{(9)}$.

Nesses estudos destaca-se a rede de sustentação para o cuidado, formada por participantes que se relacionam de modo próximo e intenso com a pessoa adoecida, sendo mais perene no tempo e espaço, configurando os núcleos de permanência. Também SE ressalta a rede de apoio para o cuidado, constituída por pessoas que participam em momentos mais pontuais, sendo esta mais mutável do que a anterior, com relacionamentos de menor intensidade afetiva ${ }^{(3)}$. Tais redes vão sofrendo modificações ao longo do tempo e espaço, o que thes confere configurações próprias e dinamicidade.

Contudo, não é tarefa fácil dar visibilidade às modificações sofridas pelas famílias e suas redes ao longo da experiência de adoecimento, dada a limitação da representação gráfica no formato de desenho plano, como tem sido até então utilizado, haja vista mostrar apenas um 'instantâneo do momento familiar'. Autores apontam as limitações do genograma e ecomapa ao simplificar dados complexos; deste modo, é necessário precaução ao utilizá-los, pois seus dados não são finais, visto que as relações são dinâmicas e instáveis ${ }^{(8)}$.

Considera-se que o desenho, por ser simbólico, pode ser interpretado como representação da realidade, sendo dotado de sentido possível de ser expresso pela linguagem ${ }^{(10)}$. No bojo da pesquisa matricial a qual este estudo se vincula, os desenhos buscam, ainda, expressar a dinamicidade das histórias familiares e seus contextos de modo a conferir-lhes visibilidade. Emprega-se o seu potencial para expressar os rearranjos, as interações e os movimentos das pessoas e famílias nas trajetórias empreendidas de busca por cuidado ao longo do tempo do adoecimento crônico, e nos diferentes espaços em que o cuidado é realizado.

A partir dessa compreensão, este estudo teve por base a vivência familiar da condição crônica, especificamente, por sofrimento mental e hipertensão arterial, respectivamente em um dos filhos e na mãe, sua principal cuidadora. Objetivamos discutir a proposição de um desenho interativo de genograma e ecomapa que pudesse representar, ao longo do tempo, o modo como uma família vivencia o adoecimento crônico concomitante em dois de seus membros. 


\section{METODOLOGIA}

Estudo de abordagem qualitativa, exploratóriodescritiva, no qual buscamos representar, por meio do desenho gráfico do genograma e do ecomapa, ferramentas que compõem o IT, o movimento de reorganização e busca, produção e gerenciamento do cuidado de uma família que vivencia dupla condição crônica, sofrimento mental por esquizofrenia em um filho e hipertensão arterial na idosa, matriarca da família.

A apreensão inicial dos dados se fez por meio do emprego da História de Vida Focal (HVF), que possibilita compreender a experiência de adoecimento conforme a perspectiva de quem a vivencia, bem como permite a descoberta, a exploração e a avaliação de como as pessoas entendem seu passado, relacionam sua experiência individual a seu contexto social, compreendem-na e thes dão sentido(11-12). Outra potencialidade dessa abordagem remete a possibilidade de apreender os diferentes "lugares" de cuidado da família, identificando os diversos participantes das suas redes, os tipos de relações tecidas e a organização do cotidiano para cuidar ao longo da história da vida familiar, com ênfase na ocorrência do adoecimento crônico.

A HVF foi operacionalizada pela entrevista em profundidade (EP), conduzida como uma conversa aberta, mas intencional, na qual é possível construir uma relação comunicativa e livre para com os participantes, exigindo a construção de um vínculo de confiança prévio(1). A EP foi desenvolvida com dois membros de uma família, nomeada de modo fictício, assim como seus membros, por "Família Jardim", especificamente a mãe, Dona Rosa, senhora idosa, e seu esposo, Senhor Cravo, também idoso. Os critérios iniciais de seleção da família para entrevista foram: estar vivenciando o adoecimento por condição crônica em um de seus membros, ser residente em Cuiabá e aceitar fazer parte do estudo. A entrevista partiu de uma questão norteadora: "Conte-me como tem sido a experiência de adoecimento e a busca por cuidados para você e sua família, e como isto tem afetado suas vidas".

O trabalho de campo ocorreu em célula de pesquisa, da qual participaram uma mestranda e uma aluna de iniciação cientifica. Foram realizados seis encontros para se completar a entrevista com Dona Rosa e Sr. Cravo, sendo que em quatro deles ocorreu a gravação de suas narrativas e em outros dois, a pedido da própria família, houve somente o registro de observação em diário de campo. O corpus de análise para este presente estudo foi constituído pelos registros transcritos das gravações decorrentes dos quatro encontros de entrevista com Dona Rosa e o Sr. Cravo.

Para análise dos dados realizamos leituras sucessivas da história narrada pela família, buscando identificar em cores diferentes os elementos que constituem as redes da família, evidenciando nessa fase os núcleos de sentido(13), os quais foram nomeados como: "participantes da rede intrafamiliar"; " participantes da rede externa"; "dados da composição familiar"; "os vínculos na rede intrafamiliar"; "os vínculos na rede externa"; "temporalidade das redes" e "dinâmica/movimento das redes". Esses núcleos foram agrupados formando três categorias de análise, sendo elas: "composição do genograma"; "redes de sustentação para o cuidado familiar" e "redes de apoio para o cuidado familiar". A partir destas categorias desenhamos, inicialmente, a composição familiar em forma do genograma. Em seguida, construímos uma "linha temporal do adoecimento da família" representando, sequencialmente, os eventos do adoecimento e cuidado.

Desenhos sequenciados do genograma e do ecomapa foram elaborados de modo a marcar, ao longo do tempo, as modificações experienciadas pela família em sua própria composição e em suas relações, intra e extrafamiliares, com destaque ao modo como o adoecimento e a própria vivência em diferentes lugares modificou sua rede de relações. Para construção dos desenhos com melhor qualidade gráfica, em meio digital e de forma interativa, utilizamos as ferramentas de desenho e animação do software Microsoft Power Point 2007.

Os aspectos éticos de pesquisa com seres humanos foram respeitados, conforme Resolução 196/96 do Conselho Nacional de Saúde, os sujeitos assinaram o Termo de Consentimento Livre e Esclarecido (TCLE). A pesquisa matricial foi aprovada pelo Comitê de Ética em Pesquisa do Hospital Universitário Julio Muller sob aprovação n 307/CEP-HUJM/06.

\section{RESULTADOS E DISCUSSÕES}

A família estudada compreende Dona Rosa, 70 anos, hipertensa, aposentada, que reside com seu marido de 76 anos, Sr. Cravo, aposentado e vendedor de vassouras fabricadas por ele, bem como com o filho, Dente de Leão de 39 anos, em sofrimento mental e aposentado, a filha Jasmim de 36 anos, auxiliar de consultório dentário, 
separada devido ao uso constante de droga do ex-marido, e com o neto, Arruda de 17 anos, estudante do terceiro ano do ensino médio e filho de Jasmim.

A família Jardim é composta, ainda, por mais sete filhos. Destes, residem na cidade de Cuiabá, João, o mais velho, de 54 anos, Emanuel, de 45 anos, Marcelo, de 43 anos, Leonardo, de 25 anos, todos eles trabalham como protéticos dentários; e Carlos, de 51 anos que trabalha em hotel. Margarida, de 53 anos, empresária e Diva, de 49 anos, professora, moram na cidade de Rondonópolis.
Esta composição familiar está retratada no genograma (Figura 1), por meio de quadrados e círculos que demonstram os homens e mulheres da família, com seus respectivos nomes fictícios e idades; a coabitação de seus membros está representada por meio de desenho de pequena casa sobreposta aos membros da família que moram juntos. Os traços representam as diferentes relações e buscam dar destaque também a qualidade dos vínculos entre os membros da família, tendo por centralidade aqueles que vivenciam a condição crônica, quais sejam, Dona Rosa e Dente de Leão.

Figura 1: Genograma de uma família na qual coexistem duas condições crônicas, Cuiabá, MT, 2009.

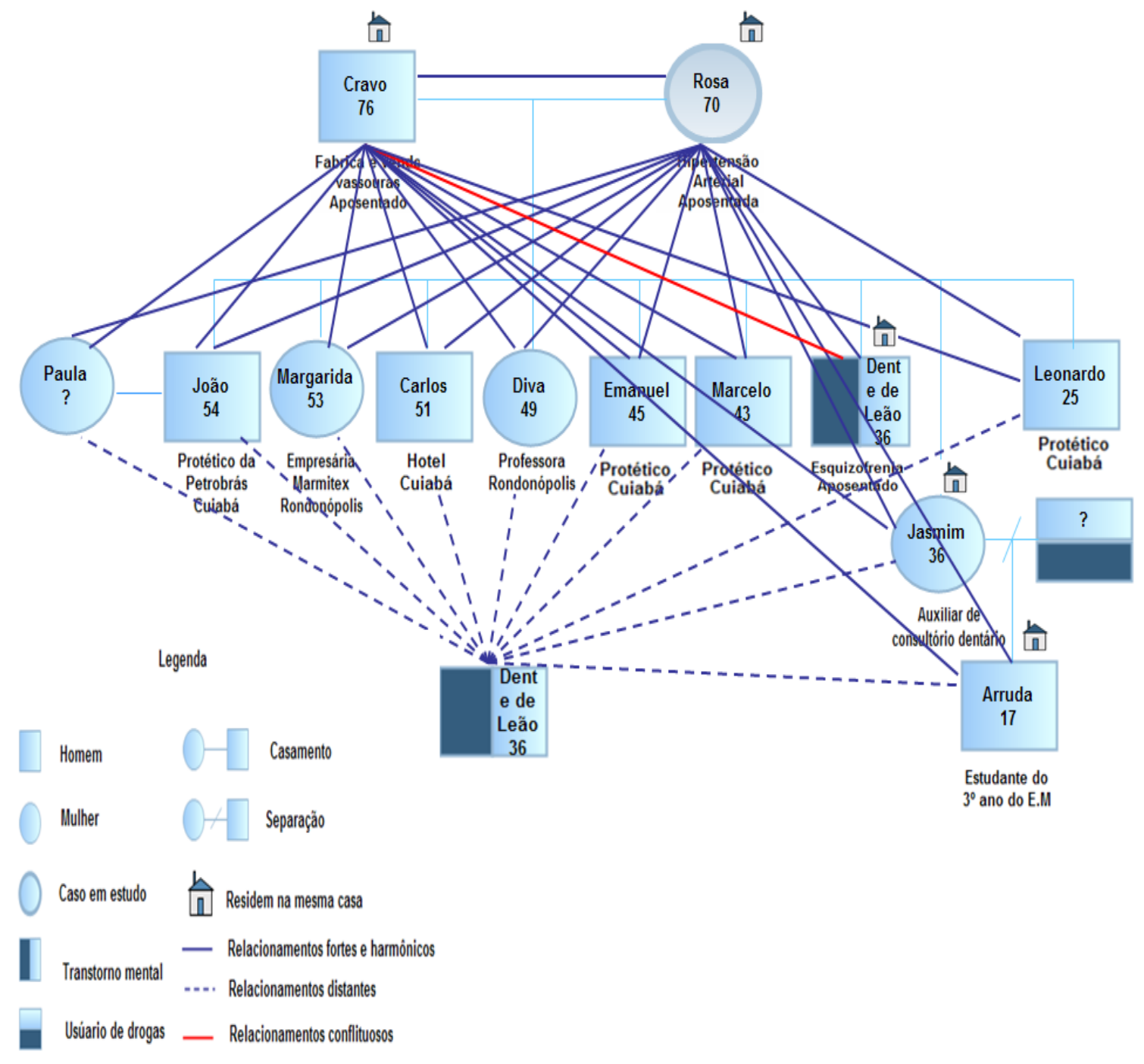

Ao expressar as relações entre os membros da família e as atribuições assumidas por eles, o genograma possibilita compreender como essas relações se conformam na experiência de adoecimento, bem como a organização da família para atender as diferentes necessidades de saúde de seus membros, por meio da explicitação dos núcleos de cuidado, entendidos como os rearranjos para o cuidado engendrados e partilhados pela família, buscando garantir a produção, gerenciamento e continuidade desse cuidado a um ou mais membro adoecido. Tais núcleos são constituídos por proximidade afetiva e estabelecidos pelo convívio entre as pessoas envolvidas no cuidado, não sendo necessariamente 
convivência em coabitação, pois pode incluir pessoas das redes de relações familiares.

Estudo sobre a trajetória de busca por cuidado de idosa e família em condição crônica por sofrimento psíquico utilizou o genograma para compreender os vários núcleos de cuidado e as redes que se conformaram ao longo da experiência de adoecimento. Evidenciou assim, que diferentes núcleos se constituem através dos cuidados prolongados que a condição crônica requer ${ }^{(14)}$. Destaca-se que no cotidiano as atribuições desempenhadas pelos membros da família se relacionam com o que eles consideram como origem de estresse ou de apoio diante do adoecimento, sendo que o reconhecimento das fontes de apoio e das redes sociais é fundamental para planejar a atenção em saúde e nelas, as intervenções de enfermagem(4).

A Figura 1 também mostra os diferentes momentos da composição familiar, de modo a explicitar a dinamicidade da família ao longo de sua experiência de adoecimento e cuidado. Nela usamos linhas contínuas para representar os relacionamentos fortes e harmônicos, as tracejadas para os relacionamentos distantes e as linhas em cor vermelha para expressar as relações conflituosas. Através das narrativas da família e do desenho do genograma podemos observar que o relacionamento de Dona Rosa com os filhos é forte e harmonioso, sendo ela a principal cuidadora da família, principalmente do filho Dente de Leão, pois sempre está presente em todos os momentos de busca por cuidado para ele. O relacionamento do Sr. Cravo com os filhos também tem características de vínculos fortes e harmônicos; porém, com o filho Dente de Leão existem momentos marcados pelo conflito. Já a relação de Dente de Leão com os irmãos se faz de modo distanciado, pela própria característica do transtorno mental que o acomete (Figura 2).

Figura 2: Sequência representativa das diferentes relações familiares, em um genograma familiar, Cuiabá, MT, 2009.

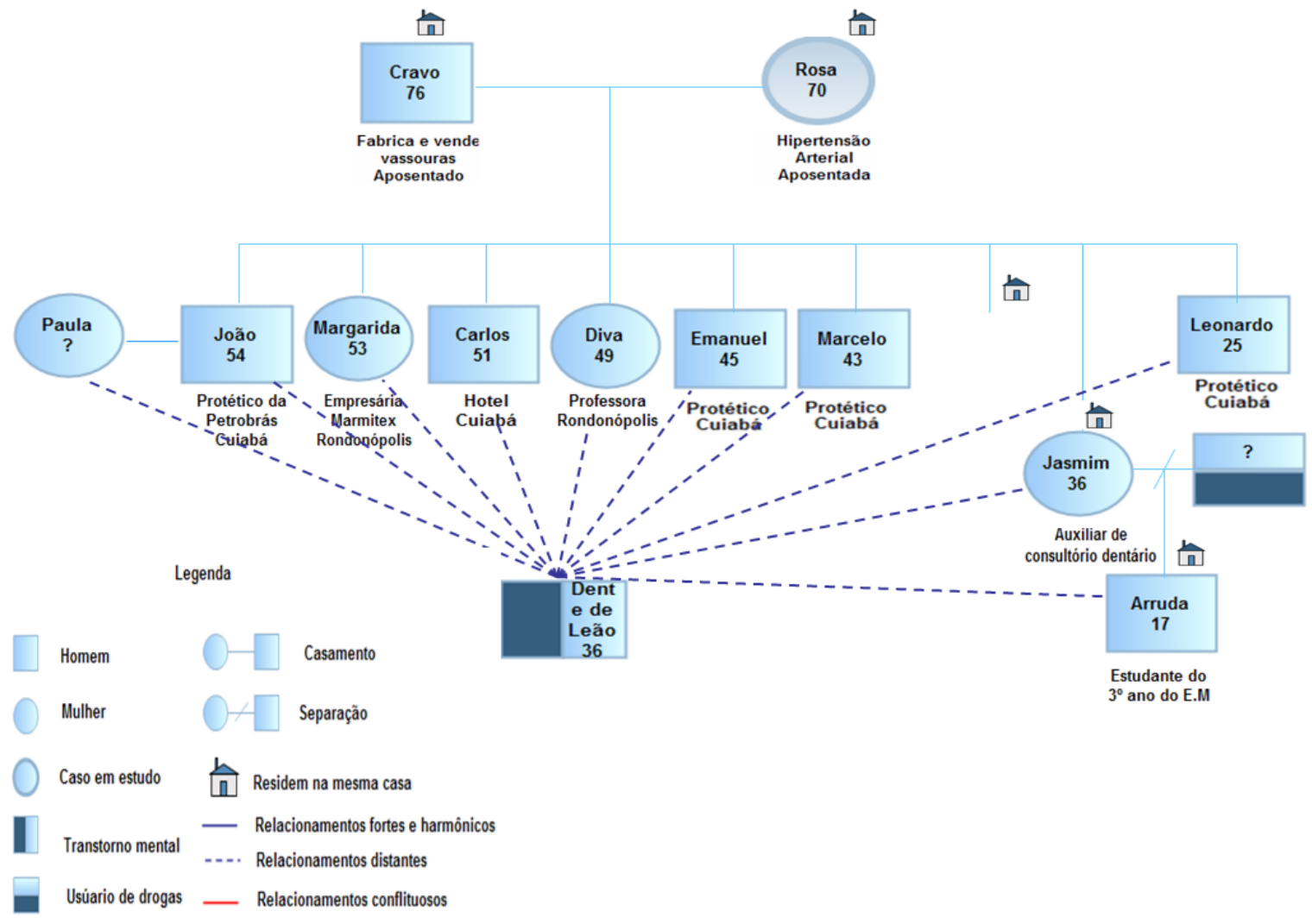

Ressaltamos a importância da utilização do genograma para compreensão dos relacionamentos e rearranjos familiares na experiência de adoecimento, já que a família está totalmente implicada no cuidado à saúde de seus membros adoecidos. Desta forma, conhecer esses relacionamentos nas variadas formas que ocorrem é fundamental para as práticas em saúde, pois "o trabalho com famílias requer habilidades do profissional para identificar a complexidade das relações que se estabelecem nas famílias, por meio das interações entre 
seus próprios membros e deles com a comunidade. Quanto mais detalhada a coleta de informações, mais eficiente será a avaliação da família para o planejamento do cuidado de enfermagem"(8).

Nos desenhos elaborados conseguimos representar estes diferentes modos de relacionamentos, fortes, fracos e conflituosos, entre pai, mãe e filhos, demonstrando, com isto, a participação de cada membro e o núcleo de cuidado familiar do jovem em sofrimento mental e sua mãe. Dentre os tipos de relacionamentos, o conflituoso tem como característica apresentar constantes atritos e desavenças, o que gera dificuldade de comunicação, desqualificação e desconfirmação do outro, podendo levar à violência física. Já o relacionamento caracterizado como distante distingue-se por haver pouco contato entre os membros familiares, principalmente de ordem emocional; ao contrário, o relacionamento forte e harmônico é definido como experiência emocional de união entre dois ou mais membros familiares, que possuem sentimentos positivos um com o outro, bem como interesses e valores em

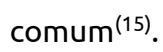

Uma das dificuldades que encontramos na construção do desenho do genograma se relacionou à forma de expressar estes diferentes relacionamentos na imagem, pois, na tentativa de representá-los, muitas linhas ficavam cruzadas no plano da figura, dificultando sua construção e a leitura das informações. Todavia, através das ferramentas de animação do programa Microsoft Power Point, conseguimos superar esta dificuldade e mostrar estes modos diferenciados de relacionamento entre mãe, pai, filho e irmãos, conferindo certa dinamicidade às relações representadas no genograma. Assim, esta dinamicidade é mais bem representada no modo "apresentação de slides"; ou seja, ao projetarmos o desenho em meio digital, sendo que a animação proporciona um desenho composto, com vários desenhos representativos (Figuras 1 e 2), evidenciando mais claramente os diferentes tipos de relacionamentos, como o conjugal, paternal, maternal e fraternal.

A Figura 3 descreve a trajetória de busca por cuidado empreendida pela família Jardim ao vivenciar o adoecimento dos seus membros.

Figura 3: Trajetória de busca por cuidado de família na qual coexistem duas condições crônicas, Cuiabá, MT, 2009.

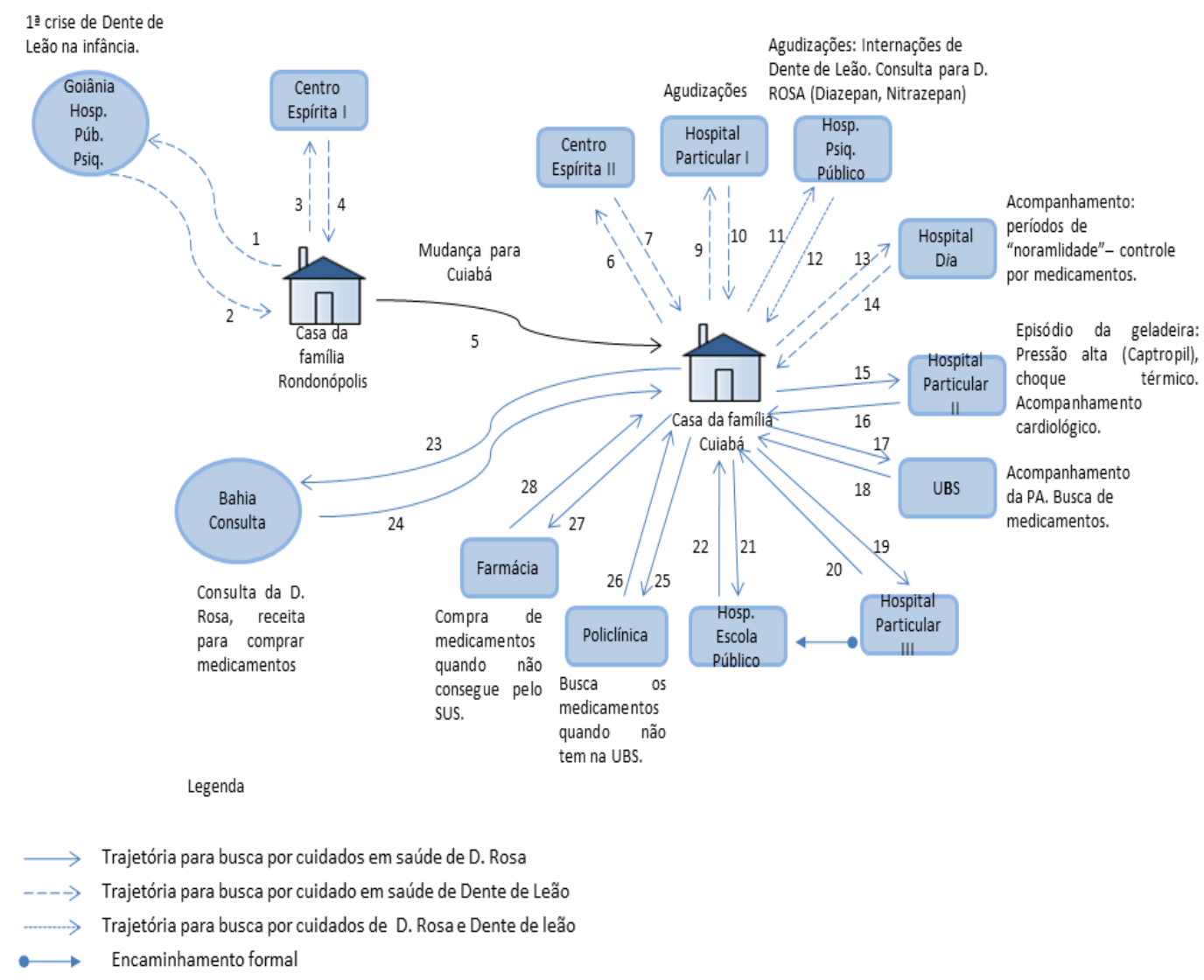


Este desenho evidencia que a busca por cuidados à saúde pela Família Jardim se iniciou em Rondonópolis, onde a mesma residia até a vinda para Cuiabá. Há, também, busca por serviços de saúde em outros estados, tanto para Dente de Leão quanto para Dona Rosa. São representados variados serviços públicos de saúde buscados, em diferentes níveis de atenção, como Hospital Público, Hospital Psiquiátrico, Unidade Básica de Saúde, Hospital Escola, e Policlínica (setas 1, 11,13, 17, 21 e 25), hospitais particulares (setas 9, 15 e 19); bem como espaços informais do sistema popular de cuidados, neste caso Centros Espíritas (seta 3 e 6).

A representação deste conjunto de percursos, em suas diversas marcações, nos dá a noção da temporalidade e espacialidade da trajetória empreendida por esta família na busca por cuidado para dois de seus membros. Tais percursos são enumerados por meio de setas, segundo a sequência temporal em que a busca ocorreu. As setas mostram, também, a direção de cada percurso que compõe a trajetória, ou seja, o movimento de busca empreendido pela família, da casa para a instituição e o retorno para a casa ou encaminhamento formal para outro recurso de saúde; o que é evidenciado, na Figura 3, somente uma vez, do Hospital Particular III para o Hospital Escola Público (setas 19 e 21).

O desenho da trajetória permite evidenciar que o gerenciamento da busca por cuidados é realizado pela família, e não por uma gestão em redes de serviços e profissionais de saúde que se responsabilizem, por meio da referência e contra-referência, pelo atendimento das necessidades das pessoas nos diferentes níveis de atenção. Constitui-se, portanto, em uma ferramenta analisadora da capacidade de integração e atenção na rede dos serviços e profissionais de saúde de uma dada localidade. Possibilita, ainda dentre outros elementos, visualizar e analisar "a forma de entrada no sistema de atendimento, as implicações do custo e acesso, a gestão do tratamento e a importância das relações de vínculo"(16).

Por meio de pequenas legendas agregadas aos percursos representados no desenho, evidenciamos as diferentes temporalidades da condição crônica, em seus períodos de agudização e normalidade; e, relacionados a eles, as buscas empreendidas pela família. As pessoas e famílias que vivenciam condições crônicas precisam de cuidados continuados e prolongados, pois essa condição alterna períodos de agudização, entendidos por essas pessoas como crise, onde a busca pelas práticas profissionais é mais intensa, o que pode ser evidenciado nos desenhos, levando a necessidade de reordenação do seu cotidiano. Também períodos de silenciamento ou normalidade da doença, momento no qual ocorrem certos equilíbrios em seus cotidianos e a busca pelas práticas profissionais é menos intensa, sendo o cuidado mais centralizado no dia a dia da família ${ }^{(17)}$.

Assim, as diversas temporalidades do adoecimento, tanto de Dona Rosa como de seu filho, expressam diferentes necessidades de cuidado e exigem a organização de redes articuladas de serviços de saúde. Permite, desse modo, avaliar a existência ou não da longitudinalidade do cuidado oferecido à pessoa em condição crônica. "A longitudinalidade pressupõe a existência de uma fonte regular de atenção e seu uso ao longo do tempo"(18) Рara tanto os serviços de saúde devem identificar a população eletiva e as pessoas dessa população que necessitam de seu atendimento, que deve ser pautado em fortes laços interpessoais que retratem a cooperação mútua entre as pessoas e profissionais de saúde ${ }^{(18)}$.

Ao desenhar o ecomapa da Família Jardim foi possível representar as redes de sustentação e de apoio tecidas por ela ao longo da experiência de adoecimento e busca por cuidado. Neste desenho procuramos evidenciar as diferentes pessoas que as compuseram, seus pertencimentos e permanência, bem como as instituições participantes e as relações existentes entre elas e a família.

No centro do desenho representamos os membros da família que coabitam com Dente de Leão e Dona Rosa e, externamente a ele, os participantes das redes distribuídos em círculos menores. Usamos linhas contínuas densas para designar os vínculos fortes e, as mais tênues, expressam os vínculos fracos. Já as pequenas setas que margeiam as linhas definidoras dos vínculos demonstram os fluxos de energia e recursos disponibilizados pelos membros da rede e/ou pela família.

A Figura 4 mostra as redes de sustentação e de apoio tecidas pela família em Rondonópolis, momento em que a família refere ter ocorrido o início do adoecimento de Dente de Leão. 
Figura 4: Ecomapa de uma família na qual coexistem duas condições crônicas. Rondonópolis, MT, 2009.

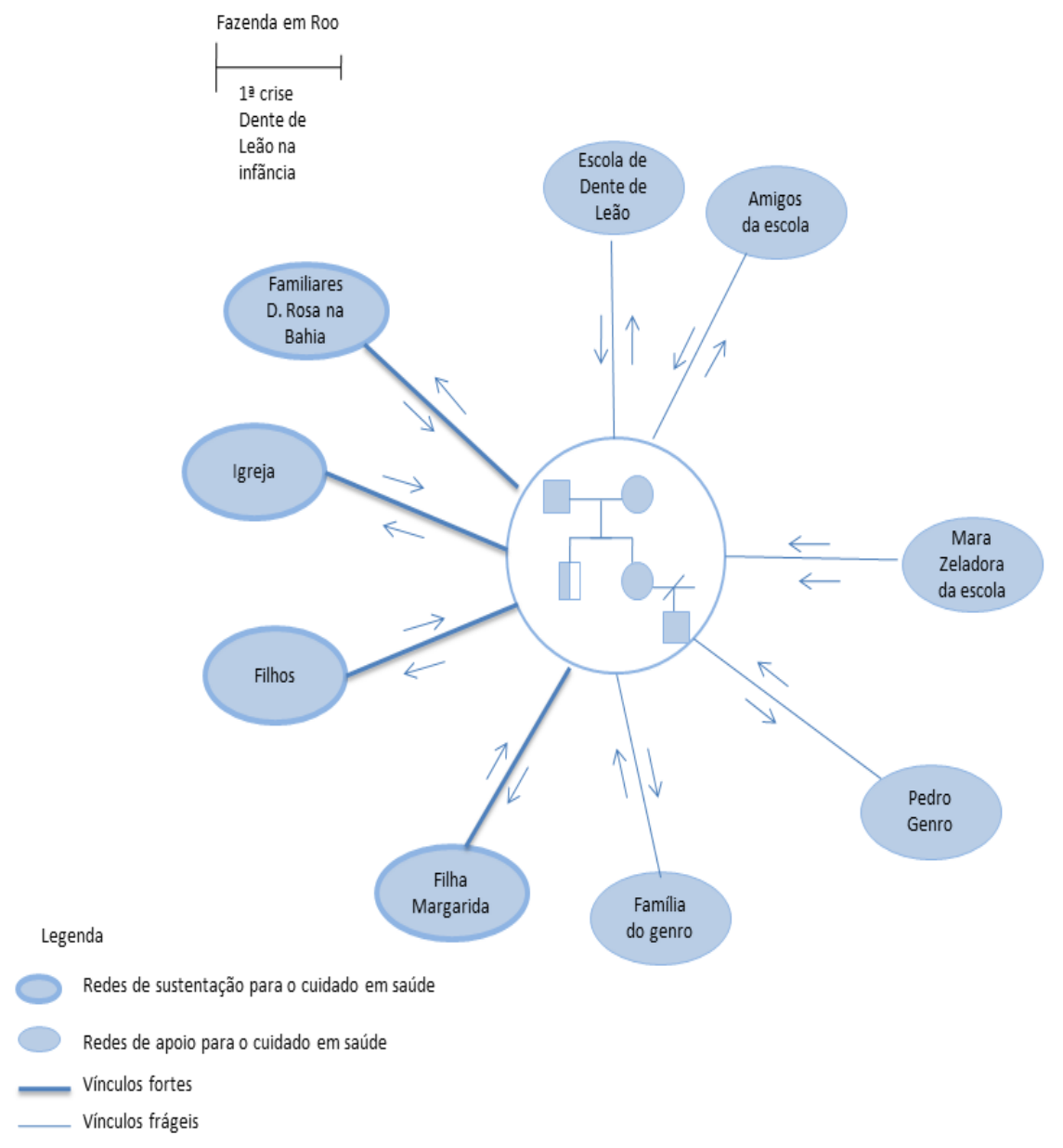

Neste período, a rede de sustentação da família era constituída pelos familiares de Dona Rosa na Bahia, pelos filhos e pela igreja que a família frequentava; já os participantes da rede de apoio eram o genro de Dona Rosa, a família do genro, a escola na qual Dente de Leão estudava, os amigos da escola e a zeladora.

Salientamos que a rede de sustentação da família, que se constitui de forma mais perene ao longo de sua história de adoecimento, configura um núcleo de permanência. Este núcleo é organizado e sustentado, principalmente, por pessoas que participam da experiência de "ser família", sendo fortes e intensos os seus relacionamentos. Já a rede de apoio, também evidenciada no desenho, assume diferentes conformações ao longo da experiência de adoecimento, sendo que os vínculos que a constitui são, em geral, de menor densidade afetiva.

A construção do ecomapa oferece elementos que permitem avaliar o suporte e recursos existentes para que a família possa cuidar e o modo como deles lança mão para produzir o seu cuidado ou buscar o cuidado profissional e outros. Tal avaliação, embora não seja de cunho quantitativo, mas da qualidade dos vínculos que a família mantém, possibilita aos profissionais de saúde compreender as conexões que a pessoa e família fazem com a comunidade e entre seus próprios membros, dando indícios importantes de que necessitam de maior atenção e apoio dos profissionais de saúde para melhorar seu bem $\operatorname{estar}^{(7)}$.

A família também buscou cuidado para Dente de Leão em Goiânia; neste período a rede se constituiu de pessoas que participaram em momentos específicos, dentre elas destacaram-se nas narrativas Laura, cunhada de Margarida, que a acolheu em sua casa, juntamente com seu irmão, Dente de Leão; e Leila, vizinha de Laura, que emprestava seu telefone para que Margarida se comunicasse com o restante da família que havia ficado em Rondonópolis.

A Figura 5 mostra as diferentes configurações do ecomapa da família Jardim na mudança para Cuiabá. Neste período da história familiar o desenho permite evidenciar que as redes para o cuidado se modificam, trazendo um maior número de participantes; 
provavelmente, por que tenha transcorrido, nesta cidade, o maior tempo da experiência de adoecimento, bem como os períodos de agudização da mesma, ampliando a busca por cuidado dessa família.

Figura 5: Diferentes configurações do ecomapa de uma família na qual coexistem duas condições crônicas. Cuiabá, MT, 2009.

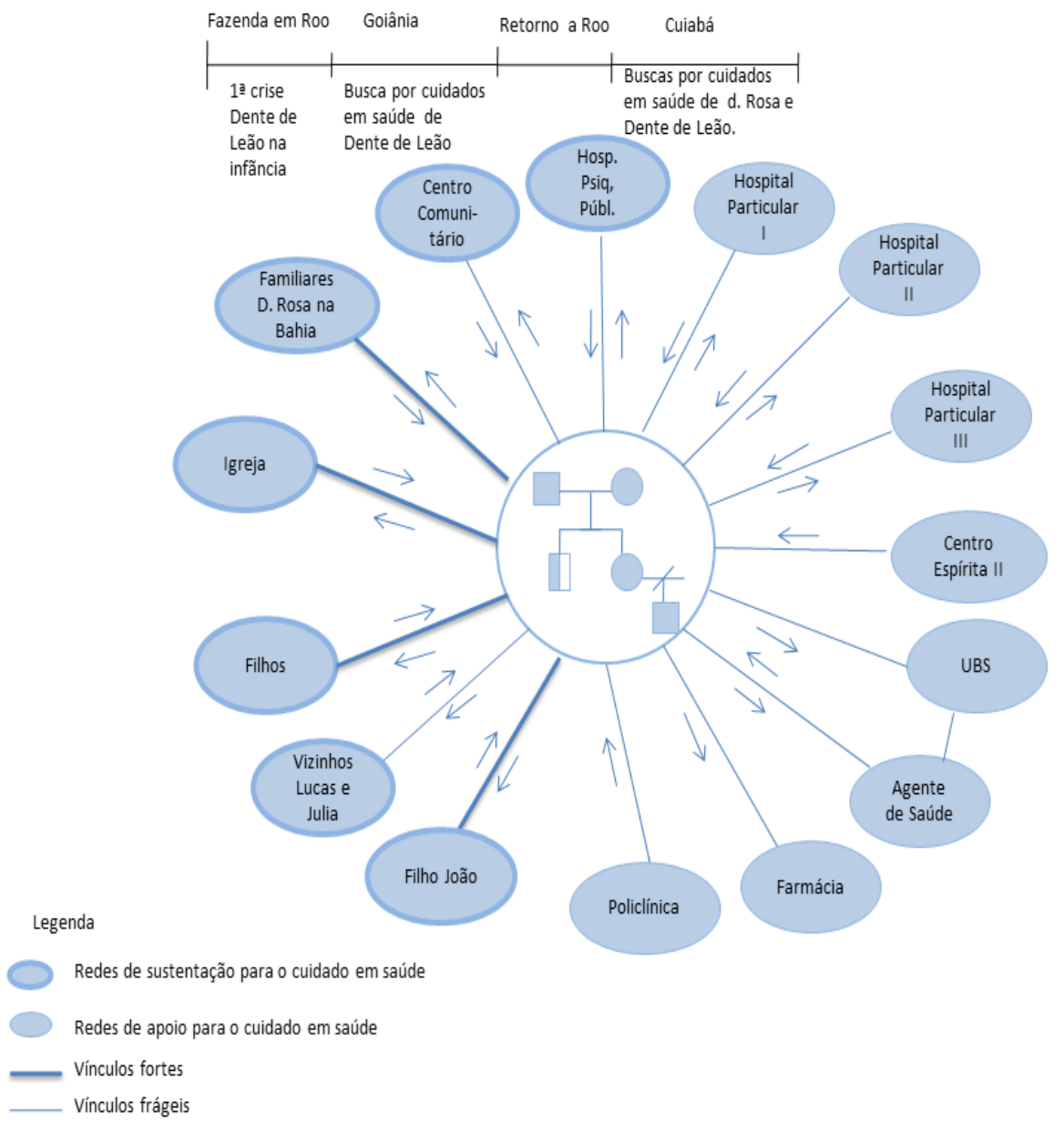

No ecomapa conseguimos representar as várias pessoas e instituições que participaram das redes para o cuidado em saúde, sendo que a rede de sustentação manteve-se mais permanente. É possível perceber o movimento devido à mudança de cidade e a inclusão de novos participantes nessa rede, como o centro comunitário, os vizinhos Lucas e Julia e o Hospital Psiquiátrico Público.

Já a rede de apoio, ao longo desse período de residência da família em Cuiabá, apresenta-se bastante modificada, com diversas instituições de saúde, principalmente hospitais, buscados para o atendimento das necessidades de saúde de Dona Rosa e de seu filho. Participam também dessa rede de apoio, a Unidade Básica de Saúde (UBS) e uma Agente Comunitária de Saúde (ACS) desta UBS; e a Policlínica e a farmácia onde a família compra os medicamentos quando não os consegue pelo Sistema Único de Saúde (SUS). Enquanto a rede de sustentação tem permanência temporal, várias modificações são evidenciadas nas redes de apoio.

Compreendemos que também o ecomapa, ao ser apresentado em meio digital, se constitui em um desenho composto que, no modo "apresentação de slides" no programa Microsoft Power Point, expressa a tecitura e movimentação das redes ao longo da experiência de adoecimento. Nesse modo de apresentação, podemos melhor evidenciar as características de reversibilidade e transitividade das redes para o cuidado à saúde ${ }^{(3)}$. Assim, os diferentes momentos da experiência de adoecimento familiar são apresentados, seguindo uma linha do tempo e relacionados aos diferentes arranjos de redes que sustentaram e apoiaram a família em cada momento dessa experiência. No ecomapa apresentado em meio digital os diferentes integrantes das redes surgem, se sucedem, reaparecem e desaparecem no decorrer das imagens, imprimindo esse movimento e dinâmica. 
As redes para o cuidado à saúde organizam-se de modo muito peculiar ao longo da biografia da pessoa/família. Através de sua tecitura, possível de ser representada pelos diversos desenhos que compõem o IT - trajetória de busca de cuidado, Genograma e Ecomapa temos a possibilidade de analisar a potencialidade para o cuidado das famílias, os recursos de que dispõem e os que podem ser acessados, bem como o modo como os serviços de saúde participam de suas redes, compondo com o cuidado realizado pela família ${ }^{(3)}$.

\section{CONCLUSÃO}

Ao longo deste estudo apresentamos três diferentes ferramentas para representar o IT da Família Jardim genograma, ecomapa e trajetória de busca por cuidado. Estas ferramentas expressas em desenhos interativos por nós propostos permitiram dar visibilidade às trajetórias empreendidas, aos rearranjos familiares e às redes para o cuidado em saúde de uma família que vivência a coexistência de duas condições crônicas - adulto jovem em sofrimento mental por esquizofrenia e sua mãe, cuidadora principal com hipertensão arterial.

Em sua capacidade sistematizadora e sintetizadora, estes diferentes desenhos puderam representar elementos importantes da história de adoecimento desta família; bem como, elementos que nos permitem compreender como a mesma gerencia a busca e produção do cuidado, tanto para Dona Rosa como para seu filho, especialmente nos diferentes rearranjos de suas redes e nos diferentes tempos e espaços da família. Para tanto, os desenhos tiveram que ser elaborados de modo a ter capacidade interativa, por meio da qual estas diferentes espacialidades e temporalidades da experiência familiar pudessem ser representadas. Lançamos mão de sequenciamentos de desenhos, construídos através do uso do software Microsoft Power Point. Esta interatividade é melhor demonstrada no modo "apresentação de slides", em meio informacional, no qual sequenciamentos de imagens aparecem na tela.

Embora esta interatividade seja bem construída e visualizada por meio do software Microsoft Power Point, persiste certa limitação na apresentação em meio impresso, visto que para utilizar todos os desenhos sequenciados ocupa-se muito espaço no texto, sendo que também a divulgação de imagens coloridas mostra-se restrita e cara.

A utilização dos desenhos de trajetória, genograma e ecomapa nas pesquisas oferece elementos que permitem avaliar o suporte e recursos existentes para que a família possa cuidar e o modo como deles lança mão para produzir o seu cuidado ou buscar o cuidado profissional e outros, isso se mostra fundamental para que possamos pensar novas práticas de atenção em saúde e nelas, as intervenções de enfermagem.

Por fim, é importante salientar que esses desenhos, sistematizadores e sintetizadores, não devem ser confundidos com o todo da vida familiar, composta por muitas dimensionalidades de experiências, devendo sempre estar ancorados com a apresentação da sua história, incluindo suas narrativas, para melhor compreensão de sua história de adoecimento e cuidado.

11(1):124-32. Available from:

http://www.fen.ufg.br/revista/v11/n1/v11n1a16.htm. 5. Moimaz SAS, Fadel CB, Yarid SD, Diniz DG. Saúde da família: o desafio de uma atenção coletiva. Ciênc. saúde

coletiva [Internet]. 2011 [cited 2013 mar 27]; 16(1):965-72.

Available from: http://dx.doi.org/10.1590/S1413-

81232011000700028.

6. Lorraine MW, Mauree L. Enfermeiras e famílias: um guia para avaliação e intervenção na família. 3 ed. São Paulo: Roca; 2002. 7. Rocha SMM, Nascimento LC, Lima RAG. Enfermagem pediátrica e abordagem da família: subsídios para o ensino de graduação. Rev. Latino-am Enfermagem [Internet]. 2002 [cited $2008 \mathrm{Jul} 20]$; 10(5):709-14. Available from:

http://www.scielo.br/scielo.php?script=sci arttext\&pid=S0104$11692002000500013 \&$ \&lng=en\&lng=en\&nrm=iso 8. Nascimento LC, Rocha SMM, Hayes VE. Contribuições do genograma e do ecomapa para o estudo de famílias em enfermagem pediátrica. Rev. Texto Contexto Enferm. [Internet]. 2005 [cited 2008 Agos 20]; 14(2):280-6. Available from: http://www.scielo.br/pdf/tce/v14n2/a17v14n2.pdf. 
9. Organização Mundial da Saúde. Cuidados inovadores para condições crônicas: componentes estruturais de ação: relatório mundial. Brasília (Brasil); 2003. 105 p.

10. Araújo CCM, Lacerda CBF. Esferas de atividade simbólica e a construção de conhecimento pela criança. Rev. bras. educ. espec. [Internet]. 2008 [cited 2009 jun 30]; 14(3):427-46.

Available from:

http://www.scielo.br/scielo.php?script=sci arttext\&pid=S141365382008000300007.

11. Hiller $M$, Bellato R, Araújo LFS. Cuidado familiar à idosa em condição crônica por sofrimento psíquico. Rev. Esc. Anna Nery [internet]. 2011 [cited 2012 jan 07]; 15(3):542-9. Available from: http://www.scielo.br/pdf/ean/v15n3/a15v15n3.pdf

12. Bellato R, Araujo LFS, Faria APS, Santos EJF, Castro P, Souza SPS, et al. A história de vida focal e suas potencialidades na pesquisa em saúde e em enfermagem. Rev. Eletr. Enf. 2008; 10(3):849-56.

13. Minayo MCS. O desafio do conhecimento: pesquisa qualitativa em saúde. 11ª ed. São Paulo: Hucitec; 2008. 14. Corrêa GHLST, Bellato R, Araújo LFS, Hiller M. Itinerário terapêutico de idosa em sofrimento psíquico e Família. Cienc Cuid Saude [internet]. 2011 [cited 2012 Mar 12]; 10(2):274-83. Available from:

http://eduem.uem.br/ojs/index.php/CiencCuidSaude/article/vie $\mathrm{w} / 10462$

15. Wendt NC, Crepaldi MA. A Utilização do Genograma como Instrumento de Coleta de Dados na Pesquisa Qualitativa. Psicol. reflex. crit. [Internet]. 2009 [cited 2009 jul]; 21(2): 302-10.

Available from:

http://www.scielo.br/pdf/prc/v21n2/a16v21n2.pdf.

16. Ferreira DC, Silva GA. Caminhos do cuidado - itinerários de pessoas que convivem com HIV. Ciênc. saúde coletiva [internet]. 2012 [cited 2013 mar 27]; 17(11):3087-98. Available from: http://www.scielosp.org/pdf/csc/v17n11/v17n11a24.pdf 17. Araújo LFS, Bellato R, Hiller M. Itinerários terapêuticos de famílias e redes para o cuidado na condição crônica: algumas experiências. In: Pinheiro R, Martins PH, editors. Avaliação em saúde na perspectiva do usuário: abordagem multicêntrica. Rio de Janeiro: UFPE; CEPESC/IMS-UERJ; Recife: UFPE; São Paulo: ABRASCO; 2009. p.203-14.

18. Starfield, B. Atenção primária: equilíbrio entre necessidades de saúde, serviços e tecnologia. Brasília (Brasil): UNESCO, Ministério da Saúde; 2002.

Artigo recebido em 29/03/2012.

Aprovado para publicação em 19/03/2013.

Artigo publicado em 30/09/2013. 